\title{
The New Architecture of Simplified Fuzzy ARTMAP for Supporting Medical Diagnostic Reasoning
}

\author{
Pranamika Kakati \\ Department of Computer Application, Girijananda \\ Chowdhury Institute of Management \\ \& Technology,Guwahati, Assam, India
}

\author{
Hemanta K. Baruah \\ Department of Statistics, Gauhati University, \\ Assam, India
}

\begin{abstract}
In this article, we would like to deal with the new architecture of Simplified Fuzzy ARTMAP which can be contributed to the extended definition of complementation of Fuzzy sets on the basis of reference function. Simplified Fuzzy ARTMAP potentially has great value in decision support applications. The extended definition of complementation is based on the fact that Fuzzy membership function and Fuzzy membership value for the complement of a Fuzzy set are two different things. On the basis of this extended definition of complementation, we have already established a new Similarity Measure for Fuzzy sets and also we have shown its effectiveness in Medical Diagnostic reasoning together with the verification of the results obtained from its application with the help of traditional Hamming Distance and Euclidean Distance measures. In this paper, our aim is to show the effectiveness of the new architecture of Simplified Fuzzy ARTMAP in supporting Medical Diagnostic reasoning. We shall apply the new Simplified Fuzzy ARTMAP to evaluate the same data, we used to show the effectiveness of the new Similarity Measure in Medical Diagnostic reasoning and validate the obtained results with the help of already verified results of the new Similarity Measure.
\end{abstract}

\section{General Terms}

Algorithm for Medical Diagnostic Reasoning

\section{Keywords}

Fuzzy set, Complement of a Fuzzy set, Fuzzy membership value, Fuzzy membership function, Fuzzy reference function, Similarity measure, Simplified Fuzzy ARTMAP, Medical Diagnostic reasoning.

\section{INTRODUCTION}

Kasuba [9] introduced Simplified Fuzzy ARTMAP (SFARTMAP) in 1993.Kasuba's SFARTMAP is a vast simplification of Carpenter and Grossberg's Fuzzy ARTMAP with reduced computational overhead and architectural redundancy. A large and ever-growing body of work now exists on applying SFARTMAP to various medical classification tasks. SFARTMAP is a Neuro -Fuzzy system which is an integration of Neural Network and Fuzzy Logic. The old existing SFARTMAP architecture is based on Zadehian concept of complementation of Fuzzy set. Zadeh [1] initiated Fuzzy sets in 1965. In Zadehian theory of Fuzzy set, it has been believed that the classical set theoretic axioms of exclusion and contradiction are not satisfied for Fuzzy sets. Zadeh defined Fuzzy set in a way where it is believed that for a Fuzzy set $\mathrm{A}$ and its complement $\mathrm{AC}$, neither $\mathrm{A} \cap \mathrm{AC}$ is null set nor $\mathrm{A}^{\mathrm{U}} \mathrm{AC}$ is the universal set which has been proved to be wrong by Baruah[2,3]. Baruah proposed that in the Zadehian definition of the complement of a Fuzzy set, Fuzzy membership function and Fuzzy membership value had been taken to be the same, which leads to the conclusion that the Fuzzy sets do not follow the set theoretic axioms of exclusion and contradiction. Therefore, Baruah has put forward an extended definition of Fuzzy set and reintroduced the notion of complement of a Fuzzy set in a way that the set theoretic axioms of exclusion and contradiction can be seen valid for Fuzzy sets also. According to Baruah, to define a Fuzzy set two functions namely- Fuzzy membership function and -Fuzzy reference function are necessary. Fuzzy membership value is the difference between Fuzzy membership function and Fuzzy reference function. Fuzzy membership function and Fuzzy membership value are two different things. Neog and Sut [4] have generalized the concept of complement of a Fuzzy set, introduced by Baruah[2,3], when the Fuzzy reference function is not zero and defined arbitrary Fuzzy union and intersection extending the definition of Fuzzy sets given by Baruah [2, 3].Therefore, it has been obvious that any result which is obtained with the help of something which itself is controversial cannot yield a suitable result. As a consequence of which we have found a need to discard those results which are based on Zadehian definition of Fuzzy sets particularly when it involves complementation. Accordingly we have established a new Similarity Measure [10,11] for Fuzzy sets based on the extended definition of complementation[2,3,4] using reference function and validate [12] the obtained results from the application of the new Similarity measure with the help of traditional Hamming Distance measure and Euclidean Distance measure which in turn prompts us to show its usefulness in Medical Diagnostic reasoning[13] . Also we have defined a new architecture [14] for SFARTMAP based on the extended definition of complementation $[2,3,4]$ together with the demonstration of its application to evaluate some example data. In this paper, our aim is to show the effectiveness of the new architecture of SFARTMAP [14] in supporting Medical Diagnostic reasoning. For that we shall apply the new architecture of SFARTMAP [14] to evaluate the collected data[13] and also verify the obtained results with the already verified results[13] by traditional Hamming Distance and Euclidean Distance measures.

The overall organization of this paper is as follows. Section 2 overview the new architecture of SFARTMAP based on the extended definition of complementation. In section 3 we apply the new SFARTMAP architecture to evaluate some collected data. In section 4 we verify the results obtained in section 3 with the already verified results obtained by the new Similarity Measure for Fuzzy sets in Medical Diagnostic reasoning. Finally, some conclusions are given in section 5 . 


\section{THE NEW SFARTMAP}

\section{ARCHITECTURE}

The algorithms for Training and Inference phases of SFARTMAP on the basis of the extended definition of complementation are as follows:

\subsection{SFARTMAP -Training phase}

Step 1: Choose an appropriate value for the vigilance parameter $(0<\rho<1)$ and a small value for $\alpha$. Set NO_OF_TRAINING_EPOCHS to the desired number of training epochs and COUNT_OF_TRAINING_EPOCHS to 0 .

Step 2: $\quad \mathrm{i} \leftarrow 1$;

\section{COUNT_OF_TRAINING_EPOCHS= \\ COUNT_OF_TRAINING_EPOCHS+1;}

\section{While(COUNT_OF_TRAINING_EPOCHS $\leq$} NO_OF_TRAINIG_EPOCHS)

Repeat Steps 3 - 12;

Step 3: Input the pattern vector $\mathrm{I}_{\mathrm{i}}=\left(\mathrm{a}_{\mathrm{i} 1}, \mathrm{a}_{\mathrm{i} 2}, \mathrm{a}_{\mathrm{i} 3}, \ldots \ldots \ldots, \mathrm{a}_{\mathrm{id}}\right)$ of dimension $d$ and its category $\mathrm{C}_{\mathrm{i}}$.

Step 4: Compute the augmented input vector using the extended definition of complementation of Fuzzy set under the 3 possible cases [14].

Step 5: If $\mathrm{AI}_{\mathrm{i}}$ is the first input in the given category $\mathrm{C}_{\mathrm{i}}$ set the top down weight vector $\mathrm{W}_{\mathrm{i}}$ as $\mathrm{AI}_{\mathrm{i}}$

$$
\text { i.e. } \mathrm{W}_{\mathrm{i}}=\mathrm{AI}_{\mathrm{i}} \text {; }
$$

Link $\mathrm{W}_{\mathrm{i}}$ to the category $\mathrm{C}_{\mathrm{i}}$

Go to step 12 .

Step 6: If $\mathrm{AI}_{\mathrm{i}}$ is an input pattern vector whose category already exits then compute the activation function $T_{j}\left(A_{i}\right)$ for each of the existing top-down weight nodes $\mathrm{W}_{\mathrm{j}}$

$$
\mathrm{T}_{\mathrm{j}}\left(\mathrm{AI}_{\mathrm{i}}\right)=\frac{\left|\mathrm{AI}_{\mathrm{i}} \wedge \mathrm{W}_{\mathrm{i}}\right|}{\alpha+\left|\mathrm{W}_{\mathrm{j}}\right|}
$$

Step 7: Choose that top-down weight node $\mathrm{k}$ which records the highest activation function

$$
\mathrm{T}_{\mathrm{k}}\left(\mathrm{AI}_{\mathrm{i}}\right)=\max _{\mathrm{j}} \mathrm{T}_{\mathrm{j}}\left(\mathrm{AI}_{\mathrm{i}}\right)
$$

Step 8: Compute the match function $\mathrm{MF}_{\mathrm{k}}\left(\mathrm{AI}_{\mathrm{i}}\right)$ of the winning node $\mathrm{k}$; linked to $\mathrm{W}_{\mathrm{k}}$

$$
\text { If } \mathrm{MF}_{\mathrm{k}}\left(\mathrm{AI}_{\mathrm{i}}\right)>\rho \text { and } \mathrm{C}_{\mathrm{i}} \text { is same as that category } \mathrm{C}_{\mathrm{k}}
$$
$\mathrm{W}_{\mathrm{k}}^{\text {old }}$ ).

Then update weight vector $\mathrm{W}_{\mathrm{k}}$ as $\mathrm{W}_{\mathrm{k}}^{\text {new }}=\mathrm{W}_{\mathrm{k}}^{\text {old }}+(\mathrm{I} \wedge$

(Here $\beta=1$ has been choosen in eqn 1 [14]

Go to step 12 .

Step 9: If $\mathrm{MF}_{\mathrm{k}}\left(\mathrm{AI}_{\mathrm{i}}\right)>\rho$ and $\mathrm{C}_{\mathrm{i}}$ is not the category $\mathrm{C}_{\mathrm{k}}$ linked to $\mathrm{W}_{\mathrm{k}}$ then

Undertake match tracking by setting $\rho$ to $\mathrm{MF}_{\mathrm{k}}\left(\mathrm{AI}_{\mathrm{i}}\right)$ and incrementing by a small value $\varepsilon$.

$$
\rho=\mathrm{MF}_{\mathrm{k}}\left(\mathrm{AI}_{\mathrm{i}}\right)+\varepsilon
$$

If some more top down weight nodes exist

Then consider the next highest winner $\mathrm{W}_{\mathrm{k}}$ among the topdown weight nodes;

Go to step 8 ;

else go to step 11

Step 10: If $\mathrm{MF}_{\mathrm{k}}\left(\mathrm{AI}_{\mathrm{i}}\right)<\rho$

then

If some more top down weight nodes exist then

Consider the next highest winner $\mathrm{W}_{\mathrm{k}}$ among the top-down weight nodes.

Go to step 8;
Else go to step 11;

Step 11: Create a new top-down weight node $\mathrm{W}_{1}$ such that $\mathrm{W}_{1}=\mathrm{AI}_{\mathrm{i}}$ and link the node to the category $\mathrm{C}_{\mathrm{i}}$;

Step 12: If no more input patterns then go to step 13 else

$$
\mathrm{i} \leftarrow \mathrm{i}+1
$$

goto Step 3;

Step 13: goto step 2;

\subsection{SFARTMAP -Inference phase}

Step 1: Let $\mathrm{W}_{\mathrm{j}}, \mathrm{j}=1,2, \ldots \ldots \ldots \ldots, \mathrm{s}$ indicate $\mathrm{s}$ top-down weight vectors obtained after training the network with a given set of training patterns;

Let $I_{i}$ be the inference pattern set each of whose category is to be inferred by the network;

$$
\mathrm{i} \leftarrow 1
$$

Step 2: Read input $\mathrm{I}_{\mathrm{i}}$;

Step 3: Compute the augmented input $\mathrm{AI}_{\mathrm{i}}$;

Step 4: for $\mathrm{j} \leftarrow 1$ to $\mathrm{s}$

Compute the activation functions

$$
\mathrm{T}_{\mathrm{j}}\left(\mathrm{AI}_{\mathrm{i}}\right)=\frac{\left|\mathrm{AI}_{\mathrm{i}} \wedge \mathrm{W}_{\mathrm{j}}\right|}{\alpha+\left|\mathrm{W}_{\mathrm{j}}\right|}
$$

Step 5: Choose the winner $\mathrm{k}$ among the $\mathrm{S}$ activation functions

$$
\mathrm{T}_{\mathrm{k}}\left(\mathrm{AI}_{\mathrm{i}}\right)=\max _{\mathrm{j}} \mathrm{T}_{\mathrm{j}}\left(\mathrm{AI}_{\mathrm{i}}\right)
$$

Step 6: Output category $C_{k}$ linked to $T_{k}\left(A I_{i}\right)$ as the one to which $\mathrm{I}_{\mathrm{i}}$ belongs to.

Step 7: If no more inference pattern vectors then exit else $\mathrm{i} \leftarrow \mathrm{i}+1$ go to step 2.

\section{APPLICATION OF THE NEW SFARTMAP ARCHITECTURE}

Now we can apply the algorithm of the new SFARTMAP on the collected data [13].

We can take the dataset of diseases [13] as Training data and the dataset of patients [13] as Testing data for the network of SFARTMAP. We represent the collected data in Table 1 and Table 2 respectively.

Table 1: dataset 1 of Disease Sets -Training Data

\begin{tabular}{|c|c|c|c|c|c|}
\hline & $\mathrm{D}_{1}$ & $\mathrm{D}_{2}$ & $\mathrm{D}_{3}$ & $\mathrm{D}_{4}$ & $\mathrm{D}_{5}$ \\
\hline $\mathrm{C}_{\mathrm{p}}$ & $(0.3,0.1)$ & $(0.2,0.1)$ & $(0.1,0.1)$ & $(0.3,0.2)$ & $(0.9,0.8)$ \\
\hline $\mathrm{C}_{\mathrm{o}}$ & $(0.7,0.4)$ & $(1.0,0.7)$ & $(0.4,0.2)$ & $(0.3,0.2)$ & $(0.2,0.2)$ \\
\hline $\mathrm{S}_{\mathrm{p}}$ & $(0.3,0.1)$ & $(0.1,0.0)$ & $(0.3,0.2)$ & $(1.0,0.8)$ & $(0.2,0.2)$ \\
\hline $\mathrm{H}_{\mathrm{d}}$ & $(0.5,0.3)$ & $(0.4,0.2)$ & $(0.9,0.6)$ & $(0.6,0.2)$ & $(0.2,0.0)$ \\
\hline $\mathrm{T}_{\mathrm{r}}$ & $(1.0,0.4)$ & $(1.0,0.7)$ & $(0.7,0.3)$ & $(0.3,0.1)$ & $(0.2,0.1)$ \\
\hline
\end{tabular}


Table 2: dataset 2 of Patient Sets -Testing (Inference) Data

\begin{tabular}{|c|c|c|c|c|}
\hline & $\mathrm{P}_{1}$ & $\mathrm{P}_{2}$ & $\mathrm{P}_{3}$ & $\mathrm{P}_{4}$ \\
\hline $\mathrm{C}_{\mathrm{p}}$ & $(0.4,0.1)$ & $(0.2,0.1)$ & $(0.5,0.0)$ & $(0.6,0.3)$ \\
\hline $\mathrm{C}_{\mathrm{o}}$ & $(0.9,0.6)$ & $(0.3,0.1)$ & $(0.3,0.2)$ & $(0.8,0.7)$ \\
\hline $\mathrm{S}_{\mathrm{p}}$ & $(0.2,0.2)$ & $(0.9,0.6)$ & $(0.4,0.0)$ & $(0.6,0.3)$ \\
\hline $\mathrm{H}_{\mathrm{d}}$ & $(0.9,0.6)$ & $(0.6,0.4)$ & $(0.9,0.8)$ & $(0.6,0.5)$ \\
\hline $\mathrm{T}_{\mathrm{r}}$ & $(0.9,0.8)$ & $(0.2,0.0)$ & $(0.9,0.8)$ & $(0.9,0.6)$ \\
\hline
\end{tabular}

Now to apply the new architecture of SFARTMAP in Medical Diagnostic reasoning, we proceed in the following manner:

Step 1: At first, we use the data from Table 1.i.e.the disease sets and apply the Training phase algorithm to train the network. From this the network will learn the diseases from its symptom characteristics.

Step 2: Then we use the data from Table 2 i.e. the patient sets and apply the Inference phase algorithm on the network. The already trained network will then classify the patients into disease categories.

Now applying both Training- and Inference- phase algorithms of new SFARTMAP architecture on the data from Table 1 and Table 2, we obtain the results as given in Table 3 .

Table 3: Activation Function values for Each Patient with every Disease

\begin{tabular}{|c|c|c|c|c|c|}
\hline & $\mathrm{D}_{1}$ & $\mathrm{D}_{2}$ & $\mathrm{D}_{3}$ & $\mathrm{D}_{4}$ & $\mathrm{D}_{5}$ \\
\hline $\mathrm{P}_{1}$ & 0.62 & 0.64 & 0.60 & 0.16 & 0.0 \\
\hline $\mathrm{P}_{2}$ & 0.34 & 0.08 & 0.48 & 0.80 & 0.28 \\
\hline $\mathrm{P}_{3}$ & 0.50 & 0.36 & 0.64 & 0.20 & 0.08 \\
\hline $\mathrm{P}_{4}$ & 0.60 & 0.54 & 0.42 & 0.26 & 0.10 \\
\hline
\end{tabular}

From Table 3 we can conclude:

Patient $P_{1}$ is suffering from disease $D_{2}$, patient $P_{2}$ is suffering from disease $D_{4}$, Patient $P_{3}$ is suffering from disease $D_{3}$, Patient $\mathrm{P}_{4}$ is suffering from disease $\mathrm{D}_{1}$.

\section{RESULT VERIFICATION}

We can verify the results obtained in section 3 with the already verified results [13] obtained from the application of the new Similarity measure in Medical Diagnostic reasoning.

We represent the verified results [13] of the new Similarity measure in Medical Diagnostic reasoning in Table 4.

Table 4: Similarity measure values for Each Patient with every Disease.

\begin{tabular}{|c|c|c|c|c|c|}
\hline & $\mathrm{D}_{1}$ & $\mathrm{D}_{2}$ & $\mathrm{D}_{3}$ & $\mathrm{D}_{4}$ & $\mathrm{D}_{5}$ \\
\hline $\mathrm{P}_{1}$ & 0.35 & 0.27 & 0.29 & 0.56 & 0.59 \\
\hline $\mathrm{P}_{2}$ & 1.04 & 0.75 & 0.33 & 0.19 & 0.42 \\
\hline $\mathrm{P}_{3}$ & 0.39 & 0.56 & 0.35 & 0.71 & 0.57 \\
\hline $\mathrm{P}_{4}$ & 0.34 & 0.39 & 0.40 & 0.51 & 0.51 \\
\hline
\end{tabular}

From Table 4 we can conclude:
Patient $P_{1}$ is suffering from disease $D_{2}$, patient $P_{2}$ is suffering from disease $D_{4}$, Patient $P_{3}$ is suffering from disease $D_{3}$, Patient $P_{4}$ is suffering from disease $D_{1}$.

Now if we compare the conclusions of Table 3 and Table 4 then we easily find that the results obtained from the application of the new architecture of SFARTMAP are absolutely valid with respect to the already verified results of the new Similarity measure for Fuzzy sets.

\section{CONCLUSION}

In this article, we have reviewed the new architecture of SFARTMAP based on the extended definition of complementation using reference function where it is believed that Fuzzy membership function and Fuzzy membership value for the complement of a Fuzzy set are two different things. In our previous research work we established a new Similarity Measure for Fuzzy sets based on the same extended definition of complementation. Here, in this paper, we have applied the new architecture of SFARTMAP to evaluate the same data we used to show the usefulness of the new Similarity Measure in supporting Medical Diagnostic reasoning. Also the results obtained have been validated comparing with the already proved results of the new Similarity Measure and finally, it has been obvious that like the new Similarity Measure for Fuzzy sets, also the new architecture of SFARTMAP is very much useful in supporting Medical Diagnostic reasoning.

\section{ACKNOWLEDGEMENT}

The author would like to thank Hemanta K. Baruah, Professor, Department of Statistics, Gauhati University,for his valuable suggestions and guidance, in preparing this article.

\section{REFERENCES}

[1] L.A.Zadeh, "Fuzzy Sets" , Information and Control, 8, pp. 338-353, 1965.

[2] Hemanta K. Baruah, "Towards Forming A Field Of Fuzzy Sets" International Journal of Energy, Information and Communications, Vol.2, Issue 1, pp. 16-20, February 2011.

[3] Hemanta K. Baruah, "The Theory of Fuzzy Sets: Beliefs and Realities", International Journal of Energy, Information and Communications, Vol. 2, Issue 2,pp. 122, May,2011.

[4] Tridiv Jyoti Neog , Dusmanta Kumar Sut, "Theory of Fuzzy Soft Sets from a New Perspective", International Journal of Latest Trends in Computing, Vol. 2, No 3, September,2011.

[5] Eulalia Szmidt, Janusz Kacprzyk, "Medical Diagnostic Reasoning Using a Similarity Measure for Intuitionistic Fuzzy Sets" Eighth Int. Conf. on IFSs, Varna, 20-21 June 2004, NIFS Vol. 10 (2004), 4, 61-69.

[6] Hong-mei Ju , Feng-Ying Wang, "A Similarity Measure for Interval -valued Fuzzy Sets and Its Application in Supporting Medical Diagnostic Reasoning”, The Tenth International Symposium on Operation Research and Its Applications(ISORA 2011), Dunhuang, China, August 28-31, 2011.

[7] Szmidt E., Kacprzyk J. (2001), "Entropy for intuitionistic Fuzzy sets". Fuzzy Sets and Systems, vol. 118, No. 3, pp. 467-477. 
[8] Hongmei Ju (2008). "Entropy for Interval-valued Fuzzy Sets",Fuzzy information and engineering, Volume 1,358366.

[9] Kasuba , Tom(1993), Simplified Fuzzy ARTMAP, AI Expert, November, pp.18-25.

[10] Pranamika Kakati (2013). “A Study on Similarity Measure for Fuzzy Sets" International Journal of Advanced Research in Computer Science and Softaware Engineering, vol. 3 Issue 8, pp.97-103, August 2013.

[11] Pranamika Kakati (2013) "A New Similarity Measure for Fuzzy Sets with the Extended Definition of Complementation"International Journal of Soft Computing and Engineering, Volume 3 Issue 4, pp.203207, September, 2013.
[12] Pranamika Kakati (2013) "A Note on the New Similarity Measure for Fuzzy sets" International Journal of Computer Applications Technology and Research, Volume 2 Issue 5, pp.601-605, September-October, 2013.

[13] Pranamika Kakati (2013) "The New Similarity Measure for Fuzzy Sets and Its application to Medical Diagnostic Reasoning" International Journal of Computer Application, Volume 80- No 15, pp. 13-17, October 2013.

[14] Pranamika Kakati (2013) "A New Architecture of Simplified Fuzzy ARTMAP with the Extended Definition of Complementation" International Journal of Computer Technology and Applications, Volume 4 Issue 5, pp. 772-784, September-October, 2013. 